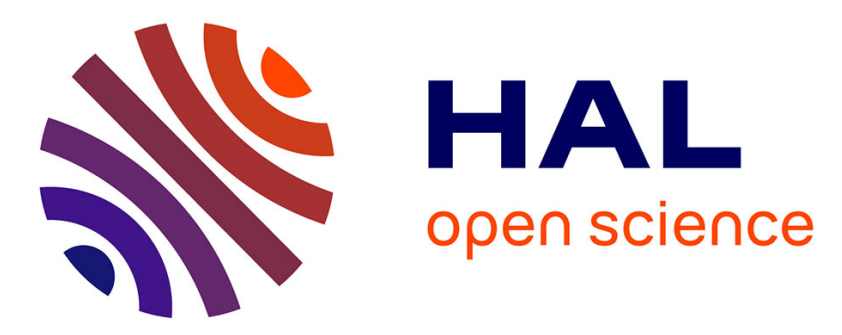

\title{
Viscosity-temperature dependence and activation energy of cellulose solutions
}

Tatiana Budtova, Patrick Navard

\section{To cite this version:}

Tatiana Budtova, Patrick Navard. Viscosity-temperature dependence and activation energy of cellulose solutions. Nordic Pulp and Paper Research Journal, 2015, Special Issue on Cellulose dissolution and regeneration: systems and interactions, 30 (01), pp.99-104. 10.3183/NPPRJ-2015-30-01-p099-104 . hal-01139845

\section{HAL Id: hal-01139845 \\ https://hal-mines-paristech.archives-ouvertes.fr/hal-01139845}

Submitted on 7 Apr 2015

HAL is a multi-disciplinary open access archive for the deposit and dissemination of scientific research documents, whether they are published or not. The documents may come from teaching and research institutions in France or abroad, or from public or private research centers.
L'archive ouverte pluridisciplinaire HAL, est destinée au dépôt et à la diffusion de documents scientifiques de niveau recherche, publiés ou non, émanant des établissements d'enseignement et de recherche français ou étrangers, des laboratoires publics ou privés. 


\section{Viscosity-temperature dependence and activation energy of cellulose solutions}

Tatiana Budtova and Patrick Navard

\begin{tabular}{l} 
KEYWORDS: Cellulose, Solutions, Rheology, \\
Viscosity, Temperature dependence, Activation energy \\
\hline SUMMARY: The dependence of cellulose solution shear \\
viscosity as a function of temperature and measurements \\
of solution activation energy are reviewed based on \\
results obtained in our laboratory and elsewhere. \\
Cellulose is not easy to solubilize. Solutions are often \\
forming aggregates and are not stable in time and with \\
temperature variations. This can be highlighted by the \\
calculation of the activation energy of the shear viscosity, \\
a parameter which is very sensitive to any change in the \\
state of the solution during the shear experiments. \\
Changes in the organization of the solution like gelation \\
or cellulose or solvent degradation are phenomena which \\
are strongly influencing the values of activation energy. \\
Cellulose solutions in three classes of solvent, ionic \\
liquids, $N$-methylmorpholine- $N$-oxide-monohydrate and \\
(7-9)\% NaOH-water with and without additives, were \\
analyzed. Cellulose was of various molecular weights. \\
The plot of the reduced activation energy versus cellulose \\
concentration shows that most points fall within a narrow \\
range of values, with a low downward curved shape, not \\
in agreement of the predictions developed for flexible \\
chains in semi-dilute regime.
\end{tabular}
ADDRESSES OF THE AUTHORS: Tatiana Budtova (tatiana.budtova@mines-paristech.fr) and Patrick Navard (patrick.navard@mines-paristech.fr): MINES ParisTech, PSL Research University, CEMEF - Centre de mise en forme des matériaux, CNRS UMR 7635, CS 10207 rue Claude Daunesse 06904 Sophia Antipolis Cedex, France

Corresponding authors: Tatiana Budtova and Patrick Navard

The flow of a polymer is a complex process which has been widely studied and modeled taking into consideration physical structures at all scales, from the molecular arrangement of the chain and its local movements to large scales features like how chains are able to move over long distances and how they may interact. Many theories flourished over years with more or less success. There is now a reasonable understanding of the motion of polymer chains in the dilute and concentrated/melt states, with still some difficulties in the semi-dilute region of polymer solutions since correlation fluctuations are large. In this region, both polymerpolymer and polymer-solvent interactions must be taken into account. With polymer flow processes being kinetically controlled, the way how flow is influenced by temperature has been studied from the start of polymer rheology. Since the easiest experimental set-up to be used is simple shear, the dependence of the shear viscosity of a polymer fluid with temperature has been quickly found to be in the general form of the Arrhenius-type (Eq 1), initially written by De Guzmán (1913), and then developed by Eyring $(1935 ; 1936)$ :

$$
\eta=A \exp (\mathrm{Ea} / R T)
$$

where $\eta$ is the viscosity, A a constant, Ea the activation energy, $\mathrm{T}$ the absolute temperature and $\mathrm{R}$ the gas constant per mole. There is no negative sign in front of Ea since this equation is derived from viscosity, not from the rate of the phenomenon as in the original Arrhenius equation.

Eq 1 can be derived from simple thermodynamic considerations where flow is seen as a local transition of a molecule or a group of molecules between one state (position before flowing) to another (position after flow occurred) having to overcome an energy barrier. One of the most common models assumes that the flow is controlled by the presence of free volume enabling molecules to jump from one place to another. Such mechanism implying a relation between free volume and viscosity was first found empirically by Batschinski (1913). For small molecules where forces resisting flow are mainly linked to interaction forces, there is a good correlation between Ea and the heat of vaporization at temperatures where there are a large fraction of free volume (Vinogradov, Malkin 1980). For polymers, in addition to overcoming attractive forces, chain entropic considerations are playing an important role. The extensive research activities in the years 1945-1970 on the rheology of polymers lead to a good experimental picture of the applicability of $E q 1$. The first conclusion is that this relation is only valid over a limited range of temperatures. As soon as the temperature interval over which $\mathrm{Ea}$ is calculated exceeds a certain temperature range (in the order of an interval of $50^{\circ} \mathrm{C}$ in most cases), the relation between the Newtonian viscosity and $1 / \mathrm{T}$ is not linear anymore.

One interesting point is that $\mathrm{Ea}$ is independent or is a very weak function of molar mass above a certain mass (Fox, Flory 1948). The classical explanation is that only a fraction of the whole chain (a segment composed of a certain number of monomers) is the relevant length scale for the flow of polymers (Kauzmann, Eyring 1940; Ventras, Duda 1977). Such consideration was thus used to explain why the activation energy of linear polymers is increasing with molar mass up to a saturation point where it is nearly independent of molar mass. Some authors used this hypothesis to estimate the mass of this segment, which was suggested to be of the same magnitude as the mass between two entanglement points (Landel et al. 1957).

The influence of the molecular structure of polymer chains on the value of the activation energy Ea was investigated by many authors. Since Ea is expressing the difficulty of moving the chain from one position to another, the intensity of interchain interactions, the presence, bulkiness and rigidity of side chains are parameters influencing the absolute value of $\mathrm{Ea}$ in the 
molten state. Increasing the size of the side groups is strongly increasing Ea (Porter, Johnson 1966). In the same way, Ea of hyperbranched polymers increases with increasing generation number (Nunez et al. 2000). Rigidity is also affecting the value of Ea. For example, polyethylene melt has an activation energy of $30 \mathrm{~kJ} / \mathrm{mol}$ (Berry, Fox 1968) while polystyrene has Ea=92 kJ/mol (Spencer, Dillon 1948) and cellulose acetate butyrate 254 $\mathrm{kJ} / \mathrm{mol}$ (Besson, Budtova 2012). Since a part of the activation energy is used for moving from one empty space to another, the proximity to glass transition temperature $\mathrm{Tg}$ is strongly influencing $\mathrm{Ea}$ in the molten state. The higher $\mathrm{Tg}$ is, the higher $\mathrm{Ea}$ will be since viscosity is usually measured in the same temperature interval (Wang, Porter 1995). Blending is also affecting the magnitude of $\mathrm{Ea}$, as for example blends of polypropylene and ethylene-octene copolymer where Ea is increasing with increasing the weight fraction of the copolymer (McNally et al. 2002).

The temperature dependence of the viscosity of polymer solutions has also been examined in details in the past. In addition to all the molecular features described above for polymer melts, the value of $\mathrm{Ea}$ is influenced by considerations of free volume, quality of solvent, polymer hydrodynamic parameters, of specific behavior of solvents (as it will be shown for the case of cellulose dissolved in ionic liquids) or by possible changes in the structure of the solution upon increasing temperature (as will be seen for cellulose solutions in $\mathrm{NaOH}$-water which are gelling). The large amount of published data on flexible chain polymers in solutions is not giving a clear, unified picture of the variation of Ea versus polymer concentration. As soon as the molar mass is large, the contribution of the polymer chain to the energy needed to flow is larger than the one of the solvent and $\mathrm{Ea}$ is increasing with polymer concentration. But the way it is increasing depends on the polymer structure and on the polymer-solvent interactions. For example, for polyvinyl acetate dissolved in two good solvents (Ferry et al. 1951), the Newtonian viscosity dependence on temperature gives a linear increase of Ea with polymer concentration, with a slope being larger for the better solvent. A detailed study of solutions of polyisobutylene in four solvents (toluene, iso-octane, carbon tetrachloride and cyclohexane), from the dilute state to the melt, shows the following behavior of Ea versus polymer concentration (Tager et al. 1963): from very low concentrations up to about $40 \%$, Ea is increasing from the value of Ea of pure solvents (a few $\mathrm{kJ} / \mathrm{mol}$ ) in a downward curved manner and then the slope is changing with an upward increase until reaching Ea for the polymer melt at $67 \mathrm{~kJ} / \mathrm{mol}$. The change of slope at high concentration is attributed by the authors to a change of type of flow, compatible with the reptation approach developed later (Doi, Edwards 1986). In the low concentration region (which is of interest for the study of cellulose solutions we consider here), Ea values of the polyisobutylene solutions versus concentration are curved downwards and the absolute value of Ea is depending on the solvent, which in this case are all good solvents. From chain flexibility considerations, these authors show that Ea is higher when the chain flexibility is lower. Upward curved Ea dependence on concentration in the low concentration region can also be found as for solutions of linear and branched polystyrene in various solvents, chloronaphtalene, alkylnaphtalene and dimethylphtalate (Yasuda et al. 1981).

As can be seen from the review above, most of the extensive experimental studies were performed before 1980, after which a lot of progress was made to understand polymer statics and dynamics. The major advances were in the semi-dilute regime. The standard model ("blob" theory) assumes that under a certain length scale, hydrodynamic interactions must be taken into account, while they are screened above this critical length scale (Heo, Larson 2008; de Gennes 1979). The polymer diffusion coefficient depends on the correlation length in the semi-dilute regime $\xi$. This length is proportional to the polymer concentration $\mathrm{C}^{3 / 4}$ (in good solvent) and $\mathrm{C}^{1}$ in $\theta$ solvents (Doi, Edwards 1986, Fujita 1990). As a consequence, depending on solvent quality, the activation energy would depend on polymer concentration with either an upward curved or a linear shape. As shown in the examples above, this is not always the case, due to possible changes in rigidity of the chain with temperature which brings divergence from $E q 1$ ( $\ln \eta$ being non-linear as a function of $1 / \mathrm{T}$ ) or possible changes in polymer solution structure and thus difficulties for estimating a value of activation energy.

The purpose of this work is to review the values of activation energies of cellulose solutions obtained in our laboratory with different cellulose sources, molar masses and solvents, compare the results with the few published data and check the validity of the measurements.

\section{Materials and methods}

\section{Cellulose solutions}

Cellulose solutions have been prepared from various cellulose sources and with various solvents. The origins of cellulose and solution preparations are given in details in the corresponding papers (references in Table 1) from where the activation energy of the viscosity has been extracted. Wood pulps (WP), bacterial cellulose (BC), spruce sulphite and wood pulp and microcrystalline cellulose (MCC) were used. Table 1 is giving details about the cellulose samples and solvents used.

Solutions were prepared with three families of solvents: ionic liquids, NMMO monohydrate and (8-9)\% $\% \mathrm{NaOH}-$ water. The main preparation features are as following.

- In ionic liquids: two ionic liquids were used, EMIMAc and BMIMCl. They can dissolve cellulose up to a rather high concentration $(25 \%)$ without activation. Cellulose must be dried in vacuum prior to dissolution. EMIMAc or $\mathrm{BMIMCl}$ and cellulose were mixed in a sealed reaction vessel and the mixtures were stirred at $80^{\circ} \mathrm{C}$ for at least $48 \mathrm{~h}$ to ensure complete dissolution. Solutions were stored at room temperature and protected against moisture absorption.

- In $\mathrm{NaOH}$-water: $\mathrm{NaOH}$-water mixture was first cooled down to $-6^{\circ} \mathrm{C}$ while cellulose is left in water at $+5^{\circ} \mathrm{C}$ for 1-2 $\mathrm{h}$ in order to swell. The cold $\mathrm{NaOH}$-water solution was added to this swollen-in-water cellulose and the mixture was stirred at about $1000 \mathrm{rpm}$ for $2 \mathrm{~h}$ at $-6^{\circ} \mathrm{C}$. 
Table 1 - Cellulose and solvents studied in our laboratory and used to calculate the shear viscosity activation energy. EMIMAc is 1-ethyl-3-methylimidazolium acetate, BMIMCl is 1-butyl-3methylimidazolium chloride, NMMO is $\mathrm{N}$-methylmorpholine $\mathrm{N}$ oxide monohydrate.

\begin{tabular}{|c|c|c|c|}
\hline Name & Description & Solvent used & Reference \\
\hline $\begin{array}{l}\text { MCC } \\
170\end{array}$ & $\begin{array}{l}\text { Microcrystalline } \\
\text { cellulose } \\
\text { DP } 170\end{array}$ & $\begin{array}{l}\text { BMIMCl and } \\
\text { EMIMAc }\end{array}$ & $\begin{array}{l}\text { Sescousse et } \\
\text { al. } 2010\end{array}$ \\
\hline $\begin{array}{l}\text { MCC- } \\
230\end{array}$ & $\begin{array}{l}\text { Microcrystalline } \\
\text { cellulose } \\
\text { DP } 230\end{array}$ & $9 \% \mathrm{NaOH}$-water & Roy 2002 \\
\hline $\begin{array}{l}\text { WP- } \\
342\end{array}$ & $\begin{array}{l}\text { Steam } \\
\text { exploded pulp } \\
\text { DP } 342\end{array}$ & $\begin{array}{l}\% \% \mathrm{NaOH}- \\
0.7 \% \mathrm{ZnO}-\text { water }\end{array}$ & Egal 2006 \\
\hline $\begin{array}{l}\text { MCC- } \\
170\end{array}$ & $\begin{array}{l}\text { Microcrystalline } \\
\text { cellulose } \\
\text { DP } 170\end{array}$ & $\mathrm{BMIMCl}$ & $\begin{array}{l}\text { Sescousse et } \\
\text { al } 2010\end{array}$ \\
\hline $\begin{array}{l}\text { MCC- } \\
300\end{array}$ & $\begin{array}{l}\text { Microcrystalline } \\
\text { cellulose } \\
\text { DP } 300\end{array}$ & EMIMAc & $\begin{array}{l}\text { Gericke et al. } \\
2009\end{array}$ \\
\hline $\begin{array}{l}\text { WP- } \\
600\end{array}$ & $\begin{array}{l}\text { Wood pulp of } \\
\text { unknown origin } \\
\text { of DP } 600\end{array}$ & NMMO & $\begin{array}{l}\text { Blachot et al. } \\
1998\end{array}$ \\
\hline $\begin{array}{l}\text { WP- } \\
1000\end{array}$ & $\begin{array}{l}\text { Spruce sulphite } \\
\text { pulp, DP } 1000\end{array}$ & EMIMAc & $\begin{array}{l}\text { Gericke et al. } \\
2009\end{array}$ \\
\hline $\mathrm{BC}$ & $\begin{array}{l}\text { Bacterial } \\
\text { cellulose, DP } \\
4420\end{array}$ & EMIMAC & $\begin{array}{l}\text { Gericke et al. } \\
2009\end{array}$ \\
\hline
\end{tabular}

Then, the solution was removed from the bath and stored at $+5{ }^{\circ} \mathrm{C}$.

- In NMMO-monohydrate: cellulose is soluble in mixtures of NMMO and water in a rather narrow temperature and NMMO concentration range. The preparation of solutions in NMMO needs to start with a hydrated NMMO-water solution (40-50\% of NMMO) where cellulose is swollen. Dissolution occurs while slowly heating up to about $120^{\circ} \mathrm{C}$ and removing water by vacuum pumping until reaching a monohydrated state of the solvent, at 13.3\% (Navard, Haudin 1981). Addition of an antioxydant like propylgallate is compulsory to avoid a strong decrease of molar mass and the production of degradation products which are dangerous (Rosenau et al. 2002). Solutions are in a liquid phase above a certain temperature which depends on concentration and must be kept below about $120^{\circ} \mathrm{C}$ to avoid hazardous exothermic events.

\section{Rheology}

Rheological measurements were all performed in steady state mode in the linear regime in order to measure the Newtonian viscosity as a function of temperature, from which the activation energy is calculated from eq 1 . Three set-ups have been used, depending on the cellulose solutions: cone and plate, plate and plate or Couette geometry (two concentric cylinders). The details can be found in the papers referenced in Table 1. For example, in the case of ionic liquids, experiments were done with a rheometer equipped with plate-plate geometry and a Peltier temperature control system. Shear rates were varied from 0.001 to $1000 \mathrm{~s}^{-1}$. Ionic liquids are hygroscopic and water decreases their viscosity and lowers their dissolution efficiency. To prevent water vapors to enter the solution during measurements through the gap, a thin film of low-viscosity silicon oil was placed around the edges of the measuring cell. In other cases, for example in the case of some $\mathrm{NaOH}$-cellulose solutions, rheological experiments were performed using a stresscontrolled rheometer with a Couette cell geometry.

Rheological results and activation energy obtained in our laboratory will also be compared with the ones available in literature, for solutions of wood pulp DP 474 in EMIMAc (Duan et al. 2011), cotton linter in $\mathrm{NaOH}-$ thiourea-urea-water (Zhang et al. 2011), wood pulp of DP 1180 dissolved in NMMO monohydrate (Kim et al. 1999), wood cellulose DP 755 in NMMO mixtures (Rozhkova et al. 1987) and cotton linters in $\mathrm{NaOH}-$ thiourea-water (Ruan et al. 2008).

\section{Results and discussion}

\section{Activation energy measurements as a way to detect solution state anomalies}

As was detailed in the introductory part, shear flow activation energy of a one-phase polymer solution has several characteristics: the viscosity is decreasing with increasing temperature, the activation energy of the solution is higher than the one of the solvent and it is increasing with increasing concentration. However, looking at some activation energy results reported in literature for cellulose solutions, these characteristics are not always found. It must be said that if all experiments are done carefully (ensuring, for example, that there is no polymer concentration change in the course of experiment, no flow instability or no solution sliding over the walls), the geometry of the measuring cell does not influence the values of viscosity measured and thus the values of the activation energy calculated. Three classes of solvents have been particularly studied due to their potential for giving real solutions (no derivatisation occurring) and offering the possibility to process cellulose solutions in order to make fibers, films, membranes, aerogels and sponges (see chapters 6, 7, 9, 11 and 12 in Navard 2013). These three classes are imidazolium-based ionic liquids, NMMO-monohydrate and (7-9)\% $\mathrm{NaOH}$-water with or without additives. Shear flow activation energy data are, to the best of our knowledge, only available for these three classes of solvents. Despite these solvents are considered as good, with one of them (NMMO) being under industrial exploitation and for ionic liquids having a promising future, their cellulose solutions are somewhat complicated and this may lead to inconsistencies in rheological measurements. A review of literature shows the following features regarding Ea data:

- Kim et al. (1999) performed a rheology study of concentrated cellulose solutions in NMMO monohydrate, with cellulose concentration between 15 and 25\%. Experiments were performed with a capillary rheometer, at a shear rate of $50 \mathrm{~s}^{-1}$. In the reported graphs showing $\ln$ (viscosity) as a function of $1 / \mathrm{T}$ (see eq.1), very low Ea values were obtained, from a few $\mathrm{kJ} / \mathrm{mol}$ to about 
$10 \mathrm{~kJ} / \mathrm{mol}$, much below the one of the solvent, $45 \mathrm{~kJ} / \mathrm{mol}$ (Navard 1982).

- Another report with a similar solvent, a mixture of NMMO, dimethylsulfoxide and water (Rozhkova 1987) gives negative Ea values (below $-30 \mathrm{~kJ} / \mathrm{mol}$ ) for cellulose concentrations around $1-8 \%$, implying that the viscosity is increasing with increasing temperatures which is not the case for cellulose-NMMO solutions.

- Negative values $(\mathrm{Ea}=-16$ and $-30 \mathrm{~kJ} / \mathrm{mol})$ were also reported in Ruan et al. 2008 for 4\% cellulose dissolved in $\mathrm{NaOH}$-thiourea-water when the temperature was above $0^{\circ} \mathrm{C}$ and above $20^{\circ} \mathrm{C}$, respectively. At lower temperatures (from -5 to $0^{\circ} \mathrm{C}$ ), Ea is positive but with a very high value, in the range of $181 \mathrm{~kJ} / \mathrm{mol}$, much larger than other reported values of cellulose dissolved in $\mathrm{NaOH}$-water (Roy et al. 2003; Egal 2006, Gavillon 2007, Roy 2002), $\mathrm{NaOH}$-urea (Gavillon 2006), $\mathrm{NaOH}-\mathrm{ZnO}$ (Egal 2006) or $\mathrm{NaOH}$-urea-thiourea (Zhang et al. 2011) where Ea is around $20-30 \mathrm{~kJ} / \mathrm{mol}$ for similar cellulose concentrations.

- Deviations from straight lines in $\ln$ (viscosity) versus $1 / T$ can be seen in the case of cellulose-ionic liquid solutions (Gericke et al. 2009; Sescousse et al 2010).

To understand why reported results are showing data which look either inconsistent or very different from what theories would predict, some considerations regarding the state of the solution and viscosity measurements are needed. It is possible to calculate the activation energy Ea of a polymer solution from shear viscosity data only when several conditions are fulfilled. A first request is that the cellulose-solvent system must be a one-phase fluid solution. This is not such a straightforward condition for cellulose solutions. For example, it is known that solutions of cellulose in $\mathrm{NaOH}$-water are gelling with its kinetics depending on temperature, concentration and presence of additives like urea, thiourea or ZnO (Roy et al. 2003; Cai, Zhang 2006; Ruan et al. 2008; Liu et al. 2011). For example, a 4\% cellulose$8 \% \mathrm{NaOH}$-water solution is gelling in more than 2 days at $5^{\circ} \mathrm{C}$, in 23 hours at $20^{\circ} \mathrm{C}$ and in $6 \mathrm{~min}$ at $30^{\circ} \mathrm{C}$. In the same solvent, a $6 \%$ cellulose solution is still gelling in more than two days at $5^{\circ} \mathrm{C}$, but is gelling in $15 \mathrm{mn}$ at $20^{\circ} \mathrm{C}$ and in a few seconds at $30^{\circ} \mathrm{C}$ (Liu et al. 2011). These measurements of gelation time were performed by oscillatory rheological measurements. Since the calculation of Ea requires collecting viscosity data over a reasonably large range of temperatures, the risk to reach the gelation region is very high. If viscosity data are collected from gelation region, the viscosity of the solution increases with temperature increase, leading to negative Ea values. This is probably the case for data reported in (Ruan et al. 2008). Very high values of Ea obtained by Ruan et al. 2008 at temperatures around $-5^{\circ} \mathrm{C}$ are most probably due to the beginning of water freezing leading to a strong increase of viscosity (Egal et al. 2007; Egal et al. 2008). Another problem is that for trying to avoid solution gelation, viscosity must be measured over a very narrow temperature and concentration range. This may be the reason why in (Roy et al. 2003), Ea is not seen depending on cellulose concentration.

A second request for calculating $\mathrm{Ea}$ is that the solution must not change its organization or its structure either as a function of time or of temperature. If this is the case, even if at a given measuring time the measurement of viscosity is performed correctly from a rheological point of view, the comparison between different temperatures or concentrations will lead to inconsistencies. Such a phenomenon can occur, for example, for cellulose solutions in NMMO monohydrate which are known to very strongly degrade cellulose if no antioxidant is added, as in Rozhkova 1987. This can be one of the reasons of extremely low values of $\mathrm{Ea}$, below the one of undegraded solvent. Other reasons can also be that at these high concentrations of cellulose $(25 \%)$, it is not molecularly dispersed anymore, providing that this ideal dispersion state can be reached (Fink et al. 2001). Combinations of such factors can thus lead to measurements of a parameter called "viscosity" which reflects different states of solution depending on the temperature, mixing state and organization, molecular weight distribution and presence of degradation products, rendering results difficult to be interpreted and compared.

Another aspect to be taken into consideration for the calculation of the activation energy is linked to the way viscosity measurements are conducted. The viscosity of a fluid is never directly measured; it is a calculated value which is coming from mechanical measurements like torque and velocities of moving parts in the case of rotational rheometers. A condition for having a meaningful viscosity value is thus that the hypothesis made for deriving the equations used for calculating the viscosity are obeyed by the measured fluid. For example, the fluid must be laminar without any instability, in particular at the edges of the rotating parts. A meaningful Ea calculation must also ensure that the flowing fluid is always in the linear regime, in order to measure the socalled Newtonian viscosity. Polymer chains have the capacity to orient and change their conformations during flow. Thus, above a certain shear rate related to the relaxation processes of the polymer chain and to the polymer-solvent friction, the viscosity will decrease. If parts of the measurements are made within this shear thinning regime, the results cannot be exploited in terms of activation energy. This may be the reason why some Ea data are difficult to understand, as the ones reported in Kim et al.1999 or in Rozhkova 1987.

A last factor is the fact that some solvents are not showing a straight line when plotting $\ln$ (viscosity) versus $1 / \mathrm{T}$, which is of course rendering the calculation of the activation of the solutions very imprecise. This is the case of imidazolium-based ionic liquids; EMIMAc and BMIMCl show a concave dependence of the logarithm of viscosity as a function of inverse temperature (Gericke et al. 2009; Sescousse et al. 2010). The concave shape is kept for cellulose dissolved in these solvents. If making the same plot but for the relative viscosity, straight lines were found indicating that the reason of non-linearity comes from the solvent properties and not from dissolved cellulose. The activation energy calculated from the linear approximation of the concave-shaped data can be then used only if comparing the results obtained in the same temperature interval.

As can be seen, the activation energy is one of the methods able to detect if viscosity measurements are meaningful or not. Too low, too high or negative values 


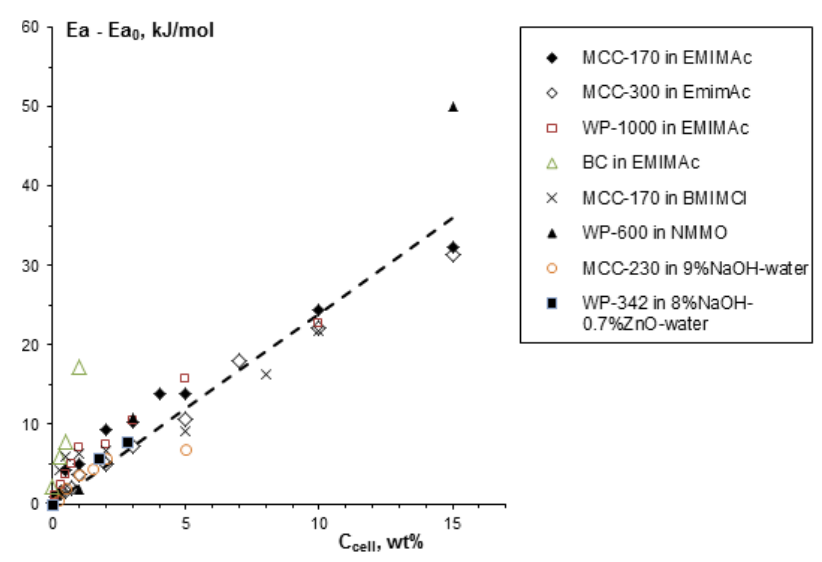

Fig 1 - Reduced activation energy of the shear viscosity of cellulose solutions in different solvents versus cellulose concentration. Dashed line corresponds to a linear approximation with the slope 2.4. The notations are detailed in Table 1.

are the signs that the state of the solution is changed either due to the flow, as it may occur when entering nonlinear regimes, or to thermodynamic or kinetic phenomena.

\section{Shear flow activation energy of cellulose solutions as a function of cellulose concentration}

A compilation of the viscosity versus temperature data obtained in our laboratory in such a way as having at best avoiding all the difficulties described in the above section allows to plot the reduced activation energy $\mathrm{Ea}-\mathrm{Ea}_{0}$ versus cellulose concentration where $\mathrm{Ea}_{0}$ is the activation energy at zero cellulose concentration (Fig l).

A first comment regarding Fig. 1 is that despite a few mis-positioned points, most values of $\mathrm{Ea}^{-\mathrm{Ea}_{0}}$ are falling in a narrow range of values. $\mathrm{Ea}^{-\mathrm{Ea}_{0}}$ is ranging from zero up to about $30-50 \mathrm{~kJ} / \mathrm{mol}$ at concentrations around $15 \%$. Although values for a single cellulose-solvent couple are slightly downward curved, we can draw an approximate straight line which gives an increment of $\mathrm{Ea}^{-\mathrm{Ea}_{0}}$ of about $2.4 \mathrm{~kJ} / \mathrm{mol}$ per $\%$. It is tempting to extrapolate to pure cellulose. Using a straight line from the data of fig 1 , it gives about $240 \mathrm{~kJ} / \mathrm{mol}$, of the same order of what is found for molten polymers such as cellulose derivative melt: cellulose acetate butyrate has $\mathrm{Ea}=254 \mathrm{~kJ} / \mathrm{mol}$ (Besson, Budtova 2012). As for all polymers, the question here is the meaning of a "mole" of chain, related to the length of the chain segment involved in the process. Another issue is that this extrapolation is conducted in the semi-dilute state, where molecules are not densely packed and fully entangled. It means that the shape of Ea could bend upwards above a certain concentration, to reach higher values than the ones extrapolated from Fig 1.

The downward curved shape of the plotted lines is not fully in line with the general predictions for flexible chain polymers in semi-dilute solutions. The reasons can be multiple, the first one being that theory is not applicable to semi-flexible chains. A last comment about Fig 1 is that if indeed $\mathrm{Ea}$ is independent of molar mass, then all $\mathrm{Ea}-\mathrm{Ea}_{0}$ values should be very similar, their difference being only linked to different cellulose-solvent interactions. Fig 1 shows that it is the case for most cellulose samples, with a small variation as a function of molar mass and solvent. There is one exception, bacterial cellulose, for which $\mathrm{Ea}$ at the highest concentration departs from the general trend. The difficulty to produce well dispersed solutions with high concentrations of this polymer is not allowing clarifying this point.

\section{Conclusions}

Changes in the organization of cellulose solutions like gelation, cellulose degradation or aggregation or shear thinning are strongly influencing the behavior of the solution during shear, an effect to which activation energy is highly sensitive. These phenomena must thus be avoided.

The three classes of solvent used (ionic liquids, $\mathrm{N}$ methylmorpholine- $\mathrm{N}$-oxide-monohydrate and $\mathrm{NaOH}$ water with and without additives) give values of the activation energies which are within a rather narrow range for cellulose of more or less comparable DP. The plot of the reduced activation energy versus cellulose concentration has a low downward curved shape, not in agreement of the predictions available for flexible chains in semi-dilute regime. This may be due to the fact that chains have some rigidity.

\section{Literature}

Batschinski, A.J. (1913): Untersuchungenüber die innereReibung der Flussigkeiten, Z. Phys. Chem. ,84, 643-706.

Berry, G.C. and Fox, T.G. (1968): The viscosity of polymers and their concentrated solutions, Adv. Polym. Sci., 5, 261-357.

Besson, F and Budtova, T. (2012): Cellulose ester-polyolefine binary blend: Morphological, rheological and mechanical properties, Eur. Polym. J., 48, 981-989.

Blachot, J-F., Brunet, N., Navard, P. and Cavaillé, J-Y. (1998): Rheological behavior of cellulose/monohydrate of $n$ methylmorpholine n-oxide solutions. Part 1: liquid state, Rheol. Acta, 37, 107-114.

Cai J. and Zhang, L.N. (2006): Unique gelation behavior of cellulose in $\mathrm{NaOH} /$ Urea aqueous solution, Biomacromolecules, 7, 183-189

De Gennes, P-G. (1979): Scalings Concepts in Polymer Physics, Cornell University Press, Ithaca, NY.

De Guzmán, J. (1913): Relación entre la Fluidez y el Calor de Fusion, Anales de la Sociedad Española de Fisica y Quimica, 11, 353-362.

Doi, M. and Edwards, S.F. (1986): The Theory of Polymer Dynamics, Clarendon Press, Oxford, University Press, New York.

Duan, X., Xu, J.X., Li, J., and Sun, Y. (2011): Preparation and rheological properties of cellulose/chitosan homogeneous solution in ionic liquid, BioResources, 6(4), 4640-4651.

Egal, M. (2006): Structure and properties of cellulose/ $\mathrm{NaOH}$ aqueous solutions, gels and regenerated objects, Thèse de doctorat, Ecole Nationale Supérieure des Mines de Paris, Sophia Antipolis, France.

Egal, M, Budtova, T., and Navard, P. (2007): Structure of Aqueous Solutions of Microcrystalline Cellulose/Sodium Hydroxide below $0^{\circ} \mathrm{C}$ and the Limit of Cellulose Dissolution, Biomacromolecules, 8, 2282-2287. 
Egal, M, Navard, P., and Budtova, T. (2008): The dissolution of microcrystalline cellulose in sodium hydroxide-urea aqueous solutions, Cellulose, 15, 361-370.

Eyring, H. (1936): Viscosity, Plasticity, and Diffusion as Examples of Absolute Reaction Rates, J. Chem. Phys., 4, 283291.

Eyring, H. (1935): The Activated Complex in Chemical Reactions, J. Chem. Phys., 3, 107-115.

Ferry, J.D., Foster, E.L., Browning, G.V., and Sawyer, W.M. (1951): Viscosities of concentrated polyvinylacetate solutions in various solvents, J. Colloid Sci., 6, 377-388.

Fink, H-P., Weigel, P., Purz, H.J., and Ganster, J. (2001): Structure formation of regenerated cellulose materials from NMMO-solutions, Progr. Polym. Sci., 26(9), 1473-1524.

Fox, T.G. Jr. and Flory, P.J. (1948): Viscosity-molecular weight and viscosity-temperature relationships for polystyrene and polyisobutylene, J. Am. Chem. Soc., 70 (7), 2384-2395.

Fujita, H. (1990): Polymer Solutions, Studies in Polymer Science 9, Elsevier, Amsterdam, pp. 222-225.

Gavillon, R. (2007): Préparation et caractérisation de matériaux cellulosiques ultraporeux, Thèse de Doctorat. Ecole Nationale Supérieure des Mines de Paris. Sophia Antipolis, France

Gericke, M., Schlufter, K., Liebert, T., Heinze, T., and Budtova, T. (2009): Rheological properties of cellulose/ionic liquid solutions: from dilute to concentrated states, Biomacromolecules, 10(5), 1188-1194.

Heo, Y. and Larson, R.G. (2008): Universal scaling of linear and nonlinear rheological properties of semidilute and concentrated polymer solutions, Macromolecules, 41, 89038915.

Kauzmann, W. and Eyring, H. (1940): The viscous flow of large molecules, J. Am. Chem. Soc., 62, 3113-3135.

Kim, S.O., Shin, W.J., Cho, H., Kim, B.C., and Chung, I.J. (1999): Rheological investigation of the anisotropic phase of cellulose-MNNO/H2O solution system, Polymer, 40, 6443-6450.

Landel, R.F., Berge, J.W., and Ferry, J.D. (1957): Viscosities of concentrated polymer solutions. IV Cellulose tributyrate, J. Colloid Sci., 12, 400-411.

Liu, W., Budtova, T., and Navard, P. (2011): Influence of ZnO on the properties of dilute and semi-dilute cellulose- $\mathrm{NaOH}$ water solutions, Cellulose, 18, 911-920.

McNally, T., McShane, P., Nally, G.M., Murphy, W.R., Cook, M and Miller, A. (2002): Rheology, phase morphology, mechanical, impact and thermal properties of polypropylene/metallocene catalysed ethylene 1-octene copolymer blends, Polymer, 43, 3785-3793.

Navard, P. and Haudin, J-M. (1981): Etude thermique de la Nméthylmorpholine $\mathrm{N}$-oxyde et de sa complexation avec l'eau, J. Thermal Anal., 22, 107-118.

Navard, P. (2013): The European Polysaccharide Network of Excellence (EPNOE). Research initiatives and results", Springer, P. Navard (ed.), Springer-Verlag Wien 2013
Navard, P. (1982): Contribution à l'étude des solutions de cellulose dans la $\mathrm{N}$-méthylmorpholine $\mathrm{N}$-oxyde, Thèse de Docteur Ingénieur. Ecole Nationale Supérieure des Mines de Paris. Sophia Antipolis, France

Nunez, C. M., Chiou, B-S., Andrady, A.L. and Khan, S.A. (2000): Solution viscosity of hyperbranched polyesters and their blends with linear polymers, Macromolecules, 33, 1720-1726.

Porter, R.S. and Johnson, J.F. (1966): The temperature dependence of polymer viscosity. The influence of shear rate and stress, J. Polym. Sci. C, 15, 365-371.

Rosenau, T., Potthast, A., Adorjan, I., Hofinger, A. Sixta, H., Firgo, H., and Kosma, P. (2002): Cellulose solutions in Nmethylmorpholine-N-oxide (NMMO) - degradation processes and stabilizers, Cellulose, 9( 3-4), 283-291.

Roy, C. (2002): Etude de mélanges de cellulose dans des solutions aqueuses de soude, Thèse de doctorat, Ecole Nationale Supérieure des Mines de Paris, Sophia Antipolis, France.

Roy, C., Budtova, T. and Navard, P. (2003): Rheological properties and gelation of aqueous cellulose- $\mathrm{NaOH}$ solutions, Biomacromolecules, 4, 259-264.

Rozhkova, O.V., Myasoyedova, V.V., and Krestov, G.A. (1987): Viscous properties of solutions of cellulose and its derivatives in the mixture methylmorpholine- $\mathrm{N}$-oxide plus dimethyl sulfoxide, Polym. Sci. USSR, 29(8), 1756-1761.

Ruan, D., Lue, A., and S Zhang, L. (2008): Gelation behaviors of cellulose solution dissolved in aqueous $\mathrm{NaOH} /$ thiourea at low temperature, Polymer, 49, 1027-1036.

Sescousse, R., Le, K.A., Ries, M.E., and Budtova, T. (2010): Viscosity of cellulose-imidazolium- based ionic liquid solutions, J. Chem. Phys., 114, 7222-7228.

Spencer, R.S. and Dillon, D.E. (1948): The viscous flow of molten polystyrene, J. Colloid Sci., 3, 163-180.

Tager, A.A., Dreval, V.Ye., and Khasina, F.A. (1963): Concentrated polymer solutions- III Viscosity of polyisobutylene solutions in various solvents, Polym. Sci. USSR, 4, 1097-1106.

Ventras, J.S. and Duda, J.L. (1977): Diffusion in polymersolvent systems. I- Reexamination of the free-volume theory, J. Polym.Sci., Polym. Phys., Ed., 15, 403-416.

Vinogradov, G.V. and Malkin, A.Ya. (1980): Rheology of Polymers, Mir publishers, Moscow, pp. 104-121.

Wang, J and Porter, R.S. (1995): On the viscosity-temperature behavior of polymer melts, Rheol. Acta, 34, 496-503.

Yasuda, K., Armstrong, R.C. and Cohen, R.E. (1981): Shear flow properties of concentrated solutions of linear and star branched polystyrenes, Rheol. Acta, 20, 163-178.

Zhang, S., Li, F-X., and Yu, J-Y. (2011): Rheological properties of cellulose- $\mathrm{NaOH}$ complex solutions: from dilute to concentrated states, Cell. Chem. Tech., 45(5-6), 313-320.

Manuscript accepted for publication February 5, 2015 